\title{
INDEX OF VOLUME 49
}

Subjects:

\section{INDEX OF ABSTRACTS}

Algebra and Theory of Numbers, 37, 216, 361, 535, 687, 849.

Analysis, 41, 217, 362, 536, 688, 851 .

Applied Mathematics, 51, 219, 369, 692, 859.

Geometry, 54, 220, 370, 538, 695, 864.

Logic and Foundations, 372, 697.

Numerical Computation, 58, 539, 698.

Statistics and Probability, 58, 221, 372, 539, 698, 865.

Topology, 59, 221, 372, 540, 699, 866.

Authors:

Agnew, R. P., 199 (41), 199 (42); Alaoglu, L., 518 (372); Albert, A. A., 518 (216), 832 (687); Albert, G. E., 519 (217), 519 (217); Alexandroff, P., 514 (540); Arens, R. F., 199 (59); Arnold, B. H., 518 (372).

Baer, R., 519 (535), 519 (535); Barnett, I. A., 199 (42); Basoco, M. A., 193 (48; 827); Beckenbach, E. F., 199 (42), 343 (218), 832 (536); Bergman, S., 199 (51), 342 (219), 830 (692), 832 (851); Bernstein, B. A., 520 (372); Bers, L., 27 (48; 831); Bing, R. H., 832 (536); Birkhoff, G., 27 (48; 831), 830 (859); Birkhoff, G. D., 199 (60); Bissinger, B. H., 831 (852), 831 (852); Blumberg, H., 514 (42); Blumenthal, L. M., 832 (866), 832 (866); Boas, R. P., 832 (536); Bourgin, D. G., 199 (60), 199 (60), 519 (373); Bowden, J., 343 (216); Brandt, A. J., (849); Branson, H. R., 514 (369); Brauer, A. T., 514 (361); Bruck, R. H., 201 (41), (849); Buck, R. C., (852), (852), (853), (864); Buseman, H., 832 (695).

Cameron, R. H., 27 (48; 666), 343 (218), 831 (688); Christie, D. E., 199 (60); Clippinger, R. F., 199 (43), 199 (43), 199 (43); Coburn, N., 27 (48; 832), 343 (219); Cohen, I. S., 199 (37); Cohen, L. W., 519 (362); Coral, M., 193 (43); Cowling, V., 832 (536); Coxeter, H. S. M., 199 (60); Curry, H. B., (859); Curtiss, J. H., 200 (58).

Day, M. M., 518 (218), 832 (688); DeCicco, J., 26 (48; 833), 27 (48; 670), 200 (54), 200 (55), 343 (220), 514 (371), 514 (371), 518 (220), 832 (695), (697), (864), (864); Dilworth, R. P., 514 (361); Dines, L. L., 343 (217); Douglas, J., 200 (55), 343 (370); Doyle, T. C., 521 (538); Dresden, M., 517 (369); Dudley, D. W., 831 (859); Duffin, R. J., 514 (362); Dunford, N., 514 (536); 832 (853); Durfee, William H., 831 (687); Dutka, J., 514 (370).

Eaton, J. E., 514 (361); Eilenberg, S., 518 (61); Erdös, P., 831 (853); Ettlinger, M. G., 343 (221); Everett, C. J., 27 (48, 826), 832 (535); Ewing, G. M., 193 (44), $832(689)$.

Federer, H., (853), (854); Feller, W. K., 343 (59), 343 (59), 831 (865); Ficken, F. A., 832 (363), 833 (363); Forsythe, G. E., 833 (692); Fort, T., 831 (689); Foster, R. M., 200 (51); Fox, A. H., 200 (51), 342 (369); Fox, R. H., 518 (373), (867); Fried, H., 831 (853); Friedman, B., (859); Friedrichs, K. O., 344 (52); Fry, C. G., 200 (45).

Gaskell, R. E., 832 (860); Geiringer, H., 342 (52); Gelbart, A., 27 (48; 831); Gould, S. H., 832 (692); Graves, L. M., 193 (61); Greenberg, H. J., 342 (220); Grove, V. G., 831 (696); Gumbel, E. J., 831 (698).

1 Numbers within parentheses refer to the page numbers for abstracts, and those outside parentheses refer to the pages for titles as listed in reports of meetings. 
Hadamard, J., 514 (370); Hailperin, T., 832 (697); Haimo, F., (37); Hall, D. W., 833 (867); Hall, N. A., 343 (44); Halmos, P. R., 200 (37), 518 (363); Hamming, R. W., 518 (363); Handelman, G. H., 832 (860); Harding, J. F., 519 (369); Harrison, G., 343 (38); Harrold, O. G., 344 (221); Hay, G. E., 830 (693); Heins, A. E., 200 (52); Heins, M. H., 833 (854), (854); Helmer, O., 343 (38); Helsel, R. G., 518 (364); Herzberger, M., 27 (52); Herzog, F., 831 (852); Hestenes, M. R., 519 (536), 833 (855); Hildebrand, F. B., 833 (693); Hille, E., 194 (44), 344 (364); Hillman, A., 27 (48; 828), 200 (58); Hoel, P. G., 194 (59); Hollcroft, T. R., 514 (371); Holtom, C., 833 (860); Hsiung, C. C., 833 (696), 833 (696), 833 (696); Hughes, H. K., 200 (45), 518 (364); Huskey, H. D., 518 (364), 831 (699); Hutchinson, L. C., 830 (860); Hyers, D. H., $521(365)$.

Isaacs, R. P., $27(48 ; 832)$.

Jacobson, N., 833 (849); James, G., 194 (45); James, R. C., 521 (373); John, F., 344 (53); Johnson, R. E., (850); Jonah, H. F. S., 193 (45).

Kaplan, W., 517 (369); Kaplansky, I., 27 (48; 826), 27 (48; 826), 833 (535); Kasner, E., 26 (48; 833), 27 (48; 671), 27 (48; 672), 27 (55), 200 (53), 200 (55), 343 (220), 514 (371), 514 (371), 831 (697), (697), (864); Kober, H., 515 (537); Kogbetliantz, E. G., 27 (48; 829), 830 (693); Korn, A., 342 (53), 830 (861).

Ladue, M. E., 343 (55); Lane, R. E., 518 (365); Lee, H. L., 831 (687); Lehmer, D. H., 520 (362); Leighton, W., 832 (536); Lengyel, B. A., 343 (39); Levenberg, K., (861); Levinson, N., (855); Levitski, J., 28 (39), 200 (38); Loomis, L. H., 514 (365); Lorch, E. R., 515 (537); Lowan, A. N., 27 (48; 520), 515 (539), (694).

McMillan, B., 193 (54), 833 (855); MacColl, L. A., (865); MacLane, S., 343 (39), 518 (61); Mandelbrojt, S., 27 (48; 829), 833 (689); Mann, H. B., 27 (48; 834), 831 (865); Marden, M., 833 (694); Martin, W. T., 27 (48; 666), 343 (218), 831 (688); Menger, K., 193 (56), 193 (61); Merrill, L. L., 832 (861); Michael, A. D., 833 (862), 833 (862); Milgram, A. N., 193 (61); Miller, D. S., 832 (853), 833 (689); Miller, L. H., 519 (217); Millsaps, K., 194 (45); Moore, C. N., 514 (45); Morse, A. P., (856), (856); Muhly, H. T., 833 (539); Murray, F. J., (856).

Nesbitt, C. J., 193 (39); Newell, H. E., 833 (856); Niven, I., 193 (39), 193 (40).

O'Connor, R. E., 831 (850); Oldenburger, R., 51.9 (40); Opatowski, I., 518 (370), 519 (369), 834 (862); Owens, G., 521 (365).

Pall, G., 831 (850); Parker, W. V., 834 (688); Peach, M. O., 834 (862); Pepper, P. M., 193 (56); Piranian, G., 519 (218), 519 (537); Pollard, H.. 834 (538), (853); P6lya, G., 520 (366); Poritsky, H., 831 (859); Prager, W., 830 (693); Price, G. B., 518 (46); Purcell, E. J., 194 (56).

Radó, T., 518 (364), 518 (373); Randolph, J. F., (856); Reade, M., 193 (46), 193 (46); Reed, S. G., 193 (61); Rickart, C. E., 342 (62), 831 (857); Ritt, J. F., 27 (48; 827); Robinson, R. M., 27 (48; 830), 520 (218); Roever, W. H., 200 (54), 200 (56); Rosenbloom, P. C., 831 (689); Rosenthall, E., 200 (40), 200 (40); Ross, A. E., 518 (362), 832 (863).

Salem, R., 193 (46), 343 (219), 834 (690); Salzer, H. E., 27 (48; 828), 27 (48; 520), 200 (58), 515 (539), 834 (688), (694), (698); Schaeffer, A. C., 194 (48; 215); Schafer, A. T., (865); Schatten, R., 515 (366); Scheffé, H., 343 (221), 834 (698); Schwartz, H. M., 200 (46), 834 (857); Schweigert, G. E., 518 (374); 519 (374); Schweitzer, A. R., 834 (690), 834 (690); Schwerdtfeger, H., 344 (217); Scott, W. M., 193 (39); Shanks, M. E., (867); Sheffer, I. M., 200 (47); Sherman, S., 834 (694); Shiffman, M., (857); Shohat, J. A., 28 (48; 831), (863); Smith, A. H., 193 (45); Snapper, E., 26 (48; 827); Snyder, W. S., 200 (47), 518 (366); Sobczyk, A., 832 (691); Spencer, D. E., 343 (57); Springer, C. E., 193 (57); Stoll, R. R., (850); Stone, A. H., 518 (222); Stone, D. M., 
(850), (857); Strodt, W. C., 342 (47); Swain, R.·L., 193 (62); Szász, O., 200 (48), 514 (366), 831 (691); Szegö, G., 344 (219), 344 (364).

Taylor, A. E., 515 (367); Taylor, W. C., 200 (48); Thrall, R. M., (851); Thron, W. J., 519 (367), 834 (538), 834 (538); Trjitzinsky, W. J., 201 (48); Truesdell, C. A., $832(863)$.

Ulam, S. M., 201 (49), 201 (57), 518 (367).

Valentine, F. A., 521 (368).

Wade, L. I., 515 (362); Wade, T. L., 201 (40), 201 (41), 201 (41), 201 (41); Wald, A., 831 (865), 831 (866); Wall, H. S., 518 (368), (691); Wallace, A. D., 28 (48; 837), 201 (62), 834 (699); Wang, F. T., 834 (692); Wasow, W., 342 (49); Wehausen, J. V., (858); Weil, A., 343 (41); Weinstein, A., 201 (49), 514 (368), 834 (695); Wetzel, M. D., 518 (368), (691); White, P., 834 (699); Whitney, H., 834 (538); Widder, D. V., 834 (864); Wilkins, J. E., 26 (57), 193 (49), 194 (50), 201 (50), 519 (371), 832 (858); Wolfowitz, J., 831 (539), 831 (866); Wong, Y. C., 28 (58); Wundheiler, A., 343 (41). Yagi, F., 201 (50); Young, G. S., 193 (62); Youngs, J. W. T., 344 (50), 518 (374), (867).

Zorn, M., 194 (44), 520 (372); Zygmund, A., 201 (51), (858).

\section{INDEX OF REPORTS OF MEETINGS AND MISCELLANEOUS ARTICLES}

Ayres, W. L. Reports of meetings of the American Mathematical Society: November meeting in South Bend, 192; April meeting in Chicago, 516.

Committee on available teachers of collegiate mathematics, 175, 804 .

Hedrick, E. R. See Snyder, V.

Hollcroft, T. R. Reports of meetings of the American Mathematical Society: October meeting in New York, 24; February meeting in New York, 339; April meeting in New York, 513; Summer meeting in New Brunswick, 823.

Kline, J. R. Reports of meetings of the American Mathematical Society: Annual meeting of the Society, 195.

- Occupational classification of mathematicians, 177.

- National committee on physicists and mathematicians, 473.

- A new deferment procedure for mathematicians, 797. Deferment of A.S.T.P. Tea.chers, 802.

Michal, A. D. Reports of meetings of the American Mathematical Society: November meeting in Los Angeles, 194; April meeting at Stanford University, 520.

Snyder, V. Earle Raymond Hedrick-In Memoriam, 345.

Wells, M. E. Henry Seely White-In Memoriam, 670.

White, H. S. See Wells, M. E.

\section{INDEX OF BOOK REVIEWS}

Barnes, J. L. See Gardner, M. F.

Begle, E. G. See Lefschetz, S.

Bell, P. O. See Lane, E. P.

Bergmann, P. G. Introduction to the theory of relativity. L. Infeld, 527.

Blumenthal, L. M. See Coxeter, H. S. M.

Campbell, J. W. See Synge, J. L.

Coxeter, H. S. M. Non-euclidean geometry. (Mathematical Expositions, no. 2.) L.M. Blumenthal, 679.

Craig, H. V. See Forder, H. G.

Dehn, M. See Lowinger, A. 
Ezekiel, M. Methods of correlation analysis. E. L. Welker, 347.

Ficken, F. A. See Piccard, S.

Flexner, W. W. See Lefschetz, S.

Forder, H. G. The calculus of extension. H. V. Craig, 524.

Fulton, J. F. See Ore, O.

Gardner, M. F., and Barnes, J. L. Transients in linear systems, studied by the Laplace transform. Vol. 1. D. V. Widder, 837.

Griffith, B. A. See Synge, J. L.

Halmos; P. R. Finite dimensional vector spaces. (Annals of Mathematics Studies, no. 7.) M. Kac, 349 .

Infeld, L. See Bergmann, P. G.

Kac, M. See Halmos, P. R.

Lane, E. P. A treatise on projective differential geometry. P. O. Bell, 840.

Lefschetz, S. Algebraic topology. (American Mathematical Society Colloquium Publications, vol. 27.) W. W. Flexner, 205.

- Topics in topology. (Annals of Mathematics Studies, no. 10.) E. G. Begle, 522.

Longwell, C. R. See Ore, O.

Lowinger, A. The methodology of Pierre Duhem. M. Dehn, 835.

Margenau, H. See Ore, O.

Miles, W. R. See Ore, O.

Molina, E. C. Poisson's exponential binomial limit; Table I-Individual Terms; Table II-Cumulated terms. S. S. Wilks, 678.

Neugebauer, O. See Table of arc-tan $x$.

Ore, O., Schlesinger, F., Margenau, H., Timm, J. A., Longwell, C. R., Woodruff, L. L., Miles, W. R., Fulton, J. Development of the sciences. Second series. T. Rad6, 835.

Piccard, S. Sur les ensembles de distances des ensembles de points d'un espace Euclidien. (Mémoires de l'Université de Neuchatel, vol. 13.) F. A. Ficken, 29.

Rado, T. See Ore, O.

Schlesinger, F. See Ore, O.

Schweigert, G. E. See Whyburn, G. T.

Segre, B. The non-singular cubic surfaces. V. Snyder, 350.

Sewell, W. E. Degree of approximation by polynomials in the complex domain. (Annals of Mathematics Studies, no. 9.) O. Szász, 529.

Snyder, V. See Tables; Segre, B.

Synge, J. L., and Griffith, B. A. Principles of mechanics. J. W. Campbell, 208.

Szász, O. See Sewell, W. E.

Table of arc-tan $x$. O. Neugebauer, 531 .

Tables of probability functions. Vol. II, V. Snyder, 31.

Tables of sine and cosine integrals for arguments from 10 to 100 . V. Snyder, 32.

Timm, J. A. See Ore, O.

Welker, E. L. See Ezekiel, M.

Whyburn, G. T. Analytic topology. (American Mathematical Society Colloquium Publications, vol. 28.) G. E. Schweigert, 672.

Widder, D. V. See Gardner, M. F.

Wilks, S. S. See Molina, E. C.

Woodruff, L. L. See Ore, O.

INDEX OF ADDRESSES

Bateman, H. Some simple differential difference equations and the related functions, 494. 
Blumenthal, L. M. Some imbedding theorems and characterization problems of distance geometry, 321.

Courant, R. Variational methods for the solution of problems of equilibrium and vibra. tions, 1.

Dunford, N. Spectral theory, 637.

Polya, G. On the zeros of the derivatives of a function and its analytic character, 178.

Richter, C. F. Mathematical questions in seismology, 477.

Taylor, A. E. Analysis in complex Banach spaces, 652.

Zygmund, A. Complex methods in the theory of Fourier series, 805.

\section{INDEX OF RESEARCH PAPERS}

Arnold, B. H. Decompositions of a $T_{1}$ space, 768.

Baer, R. Radical extensions and crossed characters, 701.

Bailey, R. P. On the convergence of sequences of linear operations, 63.

Basoco, M. A. On the Fourier developments of a certain class of theta quotients, 299.

Bateman, H. See Index of Addresses.

Beckenbach, E. F. The stronger form of Cauchy's integral theorem, 615.

Begle, E. G. Intersections of contractible polyhedra, 386.

Bell, E. T. Note on a conjecture due to Euler, 393.

Bell, P. O. Nerw systems of hypergeodesics defined on a surface, 575.

Bellman, R. Random summability and Fourier series, 732.

Lambert summability of orthogonal series, 932.

Bergman, S. Residue theorems of harmonic functions of three variables, 163.

Birkhoff, G. The radical of a group with operators, 751.

Blumenthal, L. M. See Index of Addresses.

Brauer, A. On the non-existence of odd perfect numbers of form $p^{\alpha} q_{1}^{2} q_{2}^{2} \cdots q_{t_{-1}}^{2} q_{t}^{4}, 712$.

- Note on the non-existence of odd perfect numbers of form $p^{\alpha} q_{1}^{2} q_{2}^{2} \cdots q_{t-1}^{2} q_{t}^{4}, 937$.

Bruck, R. H. Addendum to the paper "Generalized Fischer groups and algebras," 461.

Bruck, R. H., and Wade, T. L. The number of independent components of the tensors of given symmetry type, 470 .

Buck, R. C. A note on subsequences, 898.

Buck, R. C., and Pollard, H. Convergence and summability properties of subsequences, 924.

Campbell, A. D. Set-coordinates for lattices, 395.

Certaine, J. The ternary operation $(a b c)=a b^{-1} c$ of a group, 869.

Chang, S. C. On the quadric of Lie, 257. On the surfaces of coincidence, 900 .

Civin, P. See Roberts, J. H.

Clark, C. E. On the join of two complexes, 126.

- The Betti groups of the product of two normal spaces, 307. The Betti groups of symmetric and cyclic products, 450 .

Courant, R. See Index of Addresses.

Davids, N. See Lowan, A. N.

Day, M. M. Uniform convexity. III, 745.

DeCicco, J. New proofs of the theorems of Beltrami and Kasner on linear families, 407.

- Extensions of certain dynamical theorems of Halphen and Kasner, 736.

- See Kasner, E.

Dines, L. L. On linear combinations of quadratic forms, 388.

Dunford, N. See Index of Addresses.

Erdös, P., and Kakutani, S. On non-denumerable graphs, 457. 
Ettlinger, M. G. On irreducible continuous curves, 569.

Federer, H., and Morse, A. P. Some properties of measurable functions, 270.

Fox, R. H. On fibre spaces. I, 555.

On fibre spaces. II, 733.

Frame, J. S. Double coset matrices and group characters, 81.

Garnea, E. G. On a new application of Jacobi polynomials in connection with the mean value theorem, 541 .

Glass, T. F., and Leighton, W. On the convergence of a continued fraction, 133.

Goffman, C. On linear spaces which may be rendered complete normed metric spaces, 611.

Golomb, M. Zeros and poles of functions defined by Taylor series, 581.

Gunderson, N. G. Some theorems on the Euler $\phi$-function, 278.

Hall, D. W. A note on primitive skew curves, 935.

Halmos, P. R. On automorphisms of compact groups, 619.

Hedge, L. B. Transformations of multiple Fourier series, 262.

Heins, A. E. A mixed boundary value problem. Some remarks on a problem of $A$. Weinstein, 130.

Helmer, $O$. The elementary divisor theorem for certain rings without chain condition, 225.

Hewitt, E. Two notes on measure theory, 719.

Hille, E., and Szegö, G. On the complex zeros of the Bessel functions, 605.

Hillman, A. P. A note on differential polynomials, 711.

Hsiung, C. C. Theory of intersection of two plane curves, 786. An invariant of intersection of two surfaces, 877.

Hughes, H. K. On a theorem of Newsom, 288.

James, R. D. On the sieve method of Viggo Brun, 422.

Kac, M. On the average number of real roots of a random algebraic equation, 314 .

- A correction to "On the average number of real roots of a random algebraic equation," 938.

Kakutani, S. See Erdös, P.

Kaplansky, I. Solution of the "problème des ménages," 784.

Kasner, E., and DeCicco, J. The geometry of velocity systems, 236.

Kincaid, W. M. On non-cut sets of locally connected continua, 399.

Kober, H. A note on approximation by rational functions, 437.

Krabill, D. M. On extension of Wronskian matrices, 593.

Lehmer, D. H. Recurrence formulas for certain divisor functions, 150.

Leighton, W. See Glass, T. F.

Levenson, A. See Lowan, A. N.

Levi, H. Exact nth derivatives, 631.

Levitzki, J. On the radical of a general ring, 462.

Lowan, A. N., Davids, N., and Levenson, A. Errata to "Table of the zeros of the Legendre polynomials of order 1-16 and the weight coefficients for Gauss' mechanical quadrature formula," 939.

MacLane, S. A conjecture of Ore on chains in partially ordered sets, 567.

Marden, M. The zeros of certain composite polynomials, 93.

Millsaps, K. Abstract polynomials in non-abelian groups, 253.

Montgomery, D., and Samelson, H. Groups transitive on the n-dimensional torus, 455.

Moody, E. I. Notes on the Bertini involution, 433.

Morse, A. P. See Federer, H.

Morse, M. Functional topology, 144.

Nielsen, K. L., and Ramsay, B. P. On particular solutions of linear partial differential equations, 156. 
Niven, I. The Pell equation in quadratic fields, 413.

Oberg, E. N. On the approximation of functions by sums of orthonormal functions, 68 .

Oldenburger, R. Expansions of quadratic forms, 136.

Ore, O. Chains in partially ordered sets, 558.

$\mathrm{Pa}, \mathrm{C}$. A transformation of Jonas surfaces, 793.

Pall, G. The distribution of integers represented by binary quadratic forms, 447 .

Piranian, G. On the convergence of certain partial sums of a Taylor series with gaps, 881.

Pollard, H. Subseries of a convergent series, 730.

- See Buck, R. C.

Polya, G. See Index of Addresses.

Poritsky, H. Field concentration near circular conductors, 417.

Price, G. B. Cauchy-Stieltjes and Riemann-Stieltjes integrals, 625.

Ramsay, B. P. See Nielsen, K. L.

Reade, M. On subharmonic functions, 894.

Richter, C. F. See Index of Addresses.

Ritt, J. F. A family of functions and its theory of contact.

Roberts, J. H., and Civin, P. Sections of continuous collections, 142.

Samelson, H. See Montgomery, D.

Sanders, S. T., Jr. A correction to "A linear transformation whose variables and coefficients are sets of points," 938.

Sard, A. The equivalence of $n$-measure and Lebesgue measure in $E_{n}, 758$.

Savage, L. J. On the crossing of extremals at focal points, 467.

Schafer, R. D. Alternative algebras over an arbitrary field, 549.

Schweigert, G. E. Minimal A-sets, infinite orbits, and fixed elements, 754.

Scott, W. M. A remark on algebras of matrices, 444.

Smiley, M. F. A comparison of algebraic, metric, and lattice betweenness, 246.

Smiley, M. F., and Transue, W. R. Applications of transitivities of betweenness in lattice theory, 280.

$\mathrm{Su}, \mathrm{B}$. On certain pairs of surfaces in ordinary space, 722.

The characteristics of asymptotic osculating quadrics of a curve on a surface, 904.

Szász, O. On sequences of polynomials and the distribution of their zeros, 377.

- On Abel and Lebesgue summability, 885.

Szegö, G. See Hille, E.

Taylor, A. E. See Index of Addresses.

Thron, W. J. Convergence regions for the general continued fraction, 913.

Transue, W. R. See Smiley, M. F.

Valentine, F. A. On the extension of a vector function so as to preserve a Lipschitz condition, 100.

Wade, T. L. See Bruck, R. H.

Webster, M. S. A convergence theorem for certain Lagrange interpolation polynomials, 114.

Wclf, F. On harmonic and analytic functions, 602.

Wong, Y. C. A note on complementary subspaces in a Riemannian space, 120.

Yagi, F. A convergence theorem for Lebesgue-Stieltjes integrals, 760.

Youngs, J. W. T. A note on separation axioms and their application in the theory of a locally connected topological space, 383.

- The additivity of the Lebesgue area, 779.

Zuckerman, H. S. On some formulas involving the divisor function, 292.

Zygmund, A. A theorem on generalized derivatives, 917.

- See Index of Addresses. 